Dansk Ultralyddiagnostisk Selskab

\title{
Ultrasound of patients with small gallbladder polyps
}

\section{Ph.d. Malene Roland V. Pedersen ${ }^{1,2}$}

${ }^{1}$ Department of Radiology, Vejle Hospital, University Hospital of Southern Denmark

2 Institute of Regional Health Research, University of Southern Denmark

Gallbladder polyps are lesion protruding into the lumen from the gallbladder wall. Gallbladder polyps are common ultrasound findings. The prevalence has been reported up to approximately $5 \%[1,2]$ but also reported higher [3].

Most polyps are benign lesions, still malignant transformation is a concern. Gallbladder polyps are typical an asymptomatic condition with benign appearance. Inflammation, skinfolds and cholecystolithiasis can be misinterpreted as polyps during ultrasonography. Gallbladder cancer has typically a poor prognosis due to its late diagnosis. Data from GLOBOCAN 2018 reports of 165000 gallbladder cancer deaths yearly world-wide [5]. Gallbladder cancer varies significant between ethnic groups, and has been reported with incidence up to 27/100 000 in American indigenous populations [6]. The risk of malignancy increases in patients with polyp size of $>10 \mathrm{~mm}$, $>50$ years of age, co-existing gallstones and/or rapid polyp growth [4].

Current guidelines recommend surgical removal of the gallbladder if polyps $>10 \mathrm{~mm}$, due to the increased risk of malignancy, and ultrasound follow-up if the polyp size is between 6-9 $\mathrm{mm}$ [4]. What about the small polyps $<6 \mathrm{~mm}$ ? A recent gallbladder polyp management study enhances that the low prevalence of gallbladder cancer and poor understanding of its natural history has led to inconsistent management policies as most guidelines are based on retrospective studies with small sample size [7].

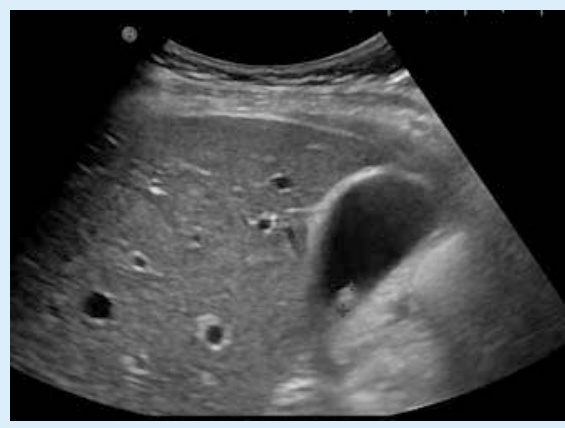

- Fig. 1

A systematic literature review including papers from 1996 to 2011 investigated growth rate and malignancy in small gallbladder polyps. Most of the studies found no correlation between growth and development of malignancy.

In 2012 our research group investigated 203 patients ( 114 woman and 89 men) with gallbladder polyps (ultrasound scan every $6^{\text {th }}$ months during a two year period) [8]. No malignancy was detected. The polyp mean size was $5 \mathrm{~mm}$, and in 175 ( $86 \%$ ) patients the polyp size was $\leq 6 \mathrm{~mm}$.

In 2020 our research group investigated long-term follow-up growth in patients with small polyps $\leq 6 \mathrm{~mm}$, and included 154 patients (100 women and 54 men) [9]. Retrospective ultrasonography reports between 2007-2009 were reviewed, and patients diagnosed with a polyp less than $6 \mathrm{~mm}$ were invited to a 1o-year follow-up ultrasonography. A total of 15 polyps had increased $2 \mathrm{~mm}$ or more during the 10 year period. The mean polyp size was $4 \mathrm{~mm}$, and no malignancy was detected. Showing that small gallbladder polyps have low probability of growth. Still, patients with gallbladder cancer have poor prognosis, and therefore it is important to iden- tify the patients who are at risk of developing a cancer.

- Fig. 1 shows a gallbladder polyp $7 \mathrm{~mm}$ in size adherent to the gallbladder wall with no acoustic shadowing. No gallstone detected.

References

[1] Afzal A, Kristiansen VB, Rosenberg J. Gall bladder polyps. Ugeskr Læger 2001; 163: 5003-5006

[2] Jørgensen T, Jensen KH. Polyps in the gallbladder. A prevalence study. Scand J Gastroenterol 1990; 25: 281-286

[3] Heitz L, Kratzer W, Gräter T et al. Gallbladder polyps - A follow-up study after 11 years. BMC Gastroenterol 2019; 19: 42 doi:10.1186/ s12876-019-0959-3

[4] Wiles R, Thoeni RF, Barbu ST et al. Management and follow-up of gallbladder polyps. Eur Radiol 2017; 27: 3856-3866

[5] Bray F, Ferlay ], Soerjomataram I et al. Global Cancer statistics 2018: GLOBOCAN estimates of incidence and mortality world-wide for 36 cancers in 185 countries. CA Cancer J Clin 2018: 68: 394-424

[6] Hundal R, Shaffer E. Gallbladder cancer: epidemiology and outcome. Clin Epidemiol 2014; 7: 99-109

[7] Valibouze C, EL Amrani M, Truant S et al. Management of gallbladder polyps. J Visc Surg 2020; 157: 413-420. doi:10.1007/s10353020-00659-8

[8] Pedersen MR, Dam C, Rafaelsen SR. Ultrasound follow-up for gallbladder polyps less than $6 \mathrm{~mm}$ may not be necessary. Dan Med J 2012; 59: A4503

[9] Rafaelsen SR, Otto PO, Pedersen MRV. Longterm ultrasound follow-up in patients with small gallbladder polyps. Dan Med I 2020; 67 (10): A06200414 